Review

\title{
Phytochemicals in Chemoprevention: A Cost-Effective Complementary Approach
}

\author{
Aayush Jain ${ }^{1}$, Chikezie O. Madu², Yi Lu ${ }^{3 凶}$ \\ 1. Departments of Biological Sciences, University of Memphis, Memphis, TN 38152. USA. \\ 2. Departments of Biological Sciences, University of Memphis, Memphis, TN 38152. USA. \\ 3. Department of Pathology and Laboratory Medicine, University of Tennessee Health Science Center, Memphis, TN 38163. USA. \\ $\triangle$ Corresponding author: Yi Lu. Ph.D. Department of Pathology and Laboratory Medicine, University of Tennessee Health Science Center, Cancer Research \\ Building, 19 South Manassas Street, Memphis, TN 38163 (USA). Tel: (901) 448-5436; Fax: (901) 448-5496; E-mail: ylu@uthsc.edu. \\ (C) The author(s). This is an open access article distributed under the terms of the Creative Commons Attribution License (https://creativecommons.org/licenses/by/4.0/). \\ See http://ivyspring.com/terms for full terms and conditions.
}

Received: 2021.01.03; Accepted: 2021.04.21; Published: 2021.04.30

\begin{abstract}
Cancer is one of the leading causes of death across the world. Although conventional cancer treatments such as chemotherapy and radiotherapy have effectively decreased cancer progression, they come with many dose-limiting side-effects. Phytochemicals that naturally occur in spices, fruits, vegetables, grains, legumes, and other common foods are surprisingly effective complements to conventional cancer treatments. These biologically active compounds demonstrate anticancer effects via cell signaling pathway interference in cancerous cells. In addition, phytochemicals protect non-cancerous cells from chemotherapy-induced side-effects. This paper addresses the not only the potential of phytochemicals quercetin, isoflavones, curcumin, catechins, and hesperidin in terms of cancer treatment and protection against side-effects of chemotherapy, but also methods for increasing phytochemical bioavailability.
\end{abstract}

Key words: anticancer, phytochemicals, healthcare economy, targeted prevention, bioavailability

\section{Introduction}

\section{Cancer as one of the Leading Causes of Mortality Worldwide}

Cancer is a major cause of mortality and is marked by the uncontrolled cell division of abnormal cells in a confined area of the body, where programmed cell death and proliferation are unbalanced. The growing health issue has caused 606,520 deaths in the U.S. in 2020 alone and is the second leading cause of death in the U.S., according to the Center for Disease Control and Prevention [1,2]. In various cancer prevention and treatment stages, we review the role of phytochemicals in chemoprevention and alleviation of chemotherapy-induced side effects.

\section{Oncogenesis as a Complex Mechanism of Cell Transformation}

Oncogenesis, where normal somatic cells are converted into cancerous cells, is a multistep process consisting of initiation, promotion, and progression, with many molecular shifts that reprogram a normal cell to experience uncontrolled cell division [3]. Tumor initiation is irreversible and involves a non-fatal mutation in the cellular DNA caused by the exposure to a particular carcinogen. Following the initial exposure to a carcinogen, cellular DNA mutates aggressively [4]. Initiation creates the potential for abnormal tissue growth and makes cells resistant to signals that inhibit cell division [5]. If prolonged exposure continues or cells that have undergone the initiation stage proliferate, promotion occurs. After pre-cancerous cells have gotten the chance to propagate, the final stage of oncogenesis, progression, occurs where the mutations built up over time result in metastatic potential [4].

Chemoprevention refers to using specific substances during oncogenesis, biological or synthetic, to reverse or inhibit carcinogenesis before it invades pre-cancerous cells [6]. During each stage of oncogenesis, phytochemicals can apply their effects in chemoprevention [7]. Chemoprevention methods can 
be grouped into primary, secondary, and tertiary methods [8]. Dietary phytochemical application is a surprisingly effective method of primary and secondary chemoprevention [8]. Phytochemicals are a bioactive compound produced by plants in primary or secondary metabolism for defending plants against external dangers, thereby assisting plants' growth and reproduction. Dietary phytochemicals naturally occur in spices, fruits, vegetables, and other plant types [9]. Since phytochemicals help defend plants from pathogens, they may either defend or harm non-plant organisms [10]. Once a few cells are exposed to a carcinogen in the initiation stage of oncogenesis, phytochemicals can encourage the detoxification of free radicals, prompting the repair of mutated cellular DNA and eliminate initiated cells through recognizing them as foreign objects [11, 12]. Even if cells have gone past the initiation stage, phytochemicals are still beneficial because they promote anti-inflammatory effects, inhibit cell proliferation, inhibit angiogenesis (development of blood vessels), and encourage apoptosis [13, 14].

\section{Conventional Forms of Cancer Treatment}

Currently, the main cancer treatments include surgery, radiation therapy, and chemotherapy. The most prevalent drugs for chemotherapy consist of hormone targeting agents, DNA-interactive agents, and antimetabolites [15]. Cancer can also be treated with therapeutic methods such as targeted therapy, immunotherapy, and hormone therapy [16]. Conventionally, radiation therapy and chemotherapy are the most accepted treatment types for any cancer because of their ability to kill cancer cells at metastasizing sites, shrinking tumor sizes. However, cancer patients' responses to these remedies vary considerably for different types of cancer. An optimal cancer treatment would kill only cancer or tumor cells, but most chemotherapy forms involve a non-specific targeting of chemotherapeutic drugs to curb uncontrolled cell division and growth [17]. The primary shortcomings of chemotherapy and radiotherapy are multidrug resistance, the reappearance of tumors, dose-limiting side effects in normal cells, and economic burden [18]. Due to the non-specific nature of chemotherapy drugs, not all cancerous cells are always eradicated from the body, which may cause a recurrence of a tumor [19]. On the other hand, phytochemicals have dual activity, meaning they exert cytotoxic effects against tumor cells while either having no effect or exerting protective effects against chemotherapy-induced side effects in normal cells. [19] Many studies have shown a lower incidence of cancer with an increase in the consumption of phytochemical-rich plant-based foods. A meta-analysis of various observational investigations established that diets with an emphasis on plant-based foods negatively correlate with cancer risk in general [20].

\section{Application Windows for Phytochemicals}

Risk factors that play a role in cancer formation include changeable factors (e.g., environmental or dietary factors) and inborn non-changeable factors (e.g., genetic predispositions). Around $10 \%$ of all types of cancer are caused by non-changeable factors, meaning around $90 \%$ of cancer types are caused by changeable risk factors [21]. Oxidizing agents and reactive oxygen species or free radicals that can be present in our food and the air lead to DNA damage. It is vital to keep a balance between the body's detoxification pathway and the intake of free radicals through our environment, illuminating the vital role of changeable risk factors such as diet in oncogenesis prevention [21]. Relative to conventional cancer treatments, plant consumption containing highly effective phytochemicals can be less of an economic burden and inconvenience than surgery and chemotherapy. [22,23] Thus, phytochemicals can help address the critically important issue in healthcare economics, as rising medical costs make conventional treatments unaffordable for many segments of the population. Additionally, this serves as a non-invasive method of preventing cancer progression and reducing the size of tumors [20]. For instance, the low incidence of bowel cancer in India is primarily attributed to the phytochemical curcumin, found in turmeric root, a spice commonly used in Indian cooking. A study in which high-risk patients for colon cancer received a dose of $480 \mathrm{mg}$ curcumin and $20 \mathrm{mg}$ quercetin saw a significant decrease in the size of polyps in their colons [24].

In recent years, there have been many findings over the predictive targeted preventative medicinal effects of phytochemicals [25]. Flavonoids have shown to combat the Warburg effect - elevated lactate secretion and glucose uptake in cancerous cells. [25] Other findings include those for certain phytochemical compounds such as curcumin in turmeric root [26], phytochemicals' efficacy for certain cancers such as pancreatic cancer [27], or the potential of phytochemical compounds in the alleviation of cancer treatment side-effects, such as isoflavones for chemotherapy-induced oral mucositis [28]. Here, we will provide an extensive summary of the research status regarding phytochemicals' potential for chemoprevention and alleviation of chemotherapyinduced side effects. 
Table 1. Summary of various phytochemicals' efficacy in chemoprevention and alleviation of chemotherapy-induced side effects

\begin{tabular}{|c|c|c|c|c|c|}
\hline Phytochemical & Type & Source & Cancers & Attenuating adverse effects & Methods to increase bioavailability \\
\hline Isoflavones & Polyphenol & $\begin{array}{l}\text { Plants of leguminosae e.g. } \\
\text { soy, chickpeas, lentils, beans }\end{array}$ & $\begin{array}{l}\text { Head and neck cell carcinoma, } \\
\text { breast, prostate, lung, cervical, } \\
\text { ovarian, remal, liver, bladder }\end{array}$ & $\begin{array}{l}\text { Neutropenia, Increased } \\
\text { Vulnerability to viral } \\
\text { infections }\end{array}$ & $\begin{array}{l}\text { Nano Drug delivery technology, } \\
\text { using active form of isoflavones } \\
\text { (aglycones) }\end{array}$ \\
\hline Quercetin & Flavonoid & $\begin{array}{l}\text { Apples, onions, cranberries, } \\
\text { red wine, whole grains }\end{array}$ & $\begin{array}{l}\text { Ovarian, prostate, oral squamous } \\
\text { cell carcinoma, esophageal } \\
\text { squamous cell carcinoma }\end{array}$ & $\begin{array}{l}\text { Gastrointestinal toxicity, } \\
\text { Neurotoxicity }\end{array}$ & $\begin{array}{l}\text { Using conjugated form of } \\
\text { quercetin, nano drug delivery } \\
\text { technology }\end{array}$ \\
\hline Curcumin & Polyphenol & $\begin{array}{l}\text { Rhizome of Curcuma longa } \\
\text { (Turmeric) }\end{array}$ & $\begin{array}{l}\text { Hepatic carcinoma, colorectal } \\
\text { cancer }\end{array}$ & $\begin{array}{l}\text { Gastrointestinal toxicity, } \\
\text { Neurotoxicity, } \\
\text { Myelosuppression }\end{array}$ & $\begin{array}{l}\text { Nano drug delivery, piperine, } \\
\text { lecithin }\end{array}$ \\
\hline Catechins & Polyphenol & Green tea & $\begin{array}{l}\text { Neuroblastoma, breast cancer, } \\
\text { prostate cancer, colorectal cancer }\end{array}$ & $\begin{array}{l}\text { Gastrointestinal toxicity, } \\
\text { Gonadotoxicity }\end{array}$ & $\begin{array}{l}\text { Nano drug delivery, molecular } \\
\text { modification, piperin }\end{array}$ \\
\hline Hesperidin & Flavonoid & $\begin{array}{l}\text { Citrus fruits e.g. orange, } \\
\text { tangerine, lemon, lime, } \\
\text { grapefruit, herbs e.g. } \\
\text { peppermint }\end{array}$ & $\begin{array}{l}\text { Skin, colon, lung, renal } \\
\text { carcinoma }\end{array}$ & $\begin{array}{l}\text { Gastrointestinal toxicity, eye } \\
\text { toxicity, hepatotoxicity }\end{array}$ & Further studies required \\
\hline
\end{tabular}

In the following review, the side-effects of chemotherapy and chemotherapeutic drugs will be discussed. Furthermore, the bioavailability and efficacy of certain dietary phytochemicals (isoflavones, quercetin, curcumin, catechins, and hesperidin) in chemoprevention will be examined as well as the role of these phytochemicals in the alleviation of chemotherapy-induced side-effects. Conversely, gaps in the foundations of phytochemical research and further implications will be discussed.

\section{Side Effects of Chemotherapy and Chemotherapeutic Drugs}

Although traditional chemotherapy is useful, it also entails many adverse effects. Many side effects of chemotherapy are dose-limiting, meaning their severity may cause a halt of cancer treatment. In both humans and animal models, chemotherapeutic drugs such as 5-FU, cisplatin, and doxorubicin can lead to neurotoxicity, gonadotoxicity, renal toxicity, hepatotoxicity, and other organ damages.

Chemotherapy-induced Nausea and Vomiting (CINV), caused by chemotherapeutic drugs, is among the most common side effects of chemotherapy treatment. Typically, the acute phase of CINV, which is moderated by 5-HT3 receptors in the intestine, occurs during the first twenty-four hours after chemotherapy administration [129]. Chemotherapy causes free radicals to form, inducing serotonin release from cells in the intestinal mucosa [29]. Serotonin then interacts with 5-HT3 receptors on intestinal wall nerves, exerting a vomiting reflex [29]. Typically, CINV can be accurately predicted and contained during the first 24 hours after chemotherapy using 5-HT3 receptor antagonists, but symptoms may be delayed, affecting the quality of life [30]. Delayed CINV usually starts 48 hours after chemotherapy administration and is mediated by a pathway with substance $\mathrm{P}$ [30]. Substance $\mathrm{P}$ is a neuropeptide constituted of an eleven amino acid chain and is part of the tachykinin neuropeptide family, behaving like a neurotransmitter and neuromodulator [32]. Chemotherapy causes substance $\mathrm{P}$ to be released from neurons and bind to NK-1 receptors in the medulla oblongata, inducing vomiting [33,34].

The mutagenic DNA damaging drugs used for chemotherapy cause skin and hair loss and have adverse effects involving bone marrow (e.g., anemia) and many other symptoms. Alkylating agents, a drug class used in cancer treatment, damages DNA by adding alkyl groups to DNA, inducing faulty nucleotide pairing, halting DNA transcription, and preventing DNA strand separation for reduplication due to cross-linking [35]. Due to alkylating agents' carcinogenic nature, patients who are administered alkylating agents have a higher risk of a more treatment-resistant form of secondary cancer (e.g., acute non-lymphocytic leukemia) [35].

Antimetabolites, another class of chemotherapeutic drugs, inhibit metabolite use, a product of metabolism involved in growth and reproduction. Therefore, these drugs inhibit cell division and growth from occurring, which is useful for halting tumor growth [36]. 5-fluorouracil (5-FU), a type of antimetabolite, is one of the most common chemotherapeutic drugs. However, recent studies have demonstrated that the administration of antimetabolites, such as 5-FU, can lead to side effects such as hair loss, photosensitivity, mood disorders, and mucositis [36-38]. Cardiotoxicity, damage to heart muscles, caused by 5-fluorouracil (5-FU) is of great concern [39]. Based on the drug dosage and drug administration method, heart muscle damage incidence ranged from $1-18 \%$ in patients treated with a fluoropyrimidine (a group of drugs, including 5-FU) [39]. Although the explicit mechanism of 5-FU induced cardiotoxicity is not known, possible mechanisms include coronary vasospasm, myocardial 
injury, or impaired oxygen delivery [41]. Coronary vasospasm, the constriction of coronary arteries causing reduced blood flow to the heart, causing ischemia (reduced blood supply to heart muscles), is the most studied mechanism of fluoropyrimidine induced cardiotoxicity [42]. Coronary vasospasm likely attributed to the cardiotoxicity patients experienced after exposure to 5-fluorouracil and had high plasma levels of endothelin-1, a vasoconstrictor present in coronary artery disease [43]. Typically, a higher rate of coronary vasospasm in patients results from a continuous infusion of the 5-FU drug rather than intermittent injections [43]. 5-FU also led red blood cells to change confirmation from a biconcave to echinocyte shape (abnormal cell membrane with thorn-like projections), which caused a decline in red blood cells' ability to transport oxygen at the usual efficiency [42].

The next section examines the potential of five different phytochemicals for chemoprevention and alleviation of the side effects discussed above.

\section{Phytochemicals for Cancer Prevention and Alleviation of Chemotherapy Side Effects}

\section{Isoflavones}

Isoflavones, a type of polyphenol (a phytochemical extensively found in plant-based foods), are perhaps one of the most controversial groups of phytochemicals with potential for chemoprevention. Isoflavones are found in the Leguminosae family plants, such as soy, lentils, chickpeas, and beans [44]. The isoflavones in soybean, such as daidzein, glycitein, and genistein, are known to have a large role in health [45]. Genistein, an isoflavone in soy, is the most studied and shown to have the most positive impact on human health, as it has been shown to have anticancer effects against head and neck squamous cell carcinoma, breast, prostate, lung, cervical, ovarian, renal, liver, and bladder cancer [46-55]. Even though isoflavones are in the inactive form in plants, known as glycosides, they convert to the active form, or aglycones, in the human intestine, as they are hydrolyzed by bacterial beta-glucosidase [56]. The active form of isoflavones (aglycones) has a higher bioavailability than glycosides, meaning they would have a higher efficacy for chemoprevention in humans [57].

Several epidemiological studies have reported a 4-7 times higher breast cancer rate in the U.S. than China and Japan, which can be attributed to the high isoflavone content in the traditional Asian diet, which includes soy products as tempeh, tofu, soy sauce, and miso [59]. Asian women with lower breast cancer prevalence had significantly higher levels of isoflavones in their plasma [59]. In general, Soy isoflavones also have significant anti-angiogenic effects, shown through increased endostatin and decreased VEGF (vascular endothelial growth factor) levels, as well as a lower tumor microvascular density [60]. Several studies have shown a much higher rate of prostate cancer in males in Western countries over Asian males, which suggests that the soy-rich foods in the traditional Asian diet potentially block prostate cancer [61]. Genistein increased transcription of p21, a Cyclin-dependent kinase inhibitor, resulting in cell cycle arrest in prostate cancer cell lines PC-3 and LNCaP [62]. In another case, both genistein and daidzein decreased cyclin B1 and increased p53 expression in LNCaP and PC-3 cell lines [63].

Although genistein sensitizes cancerous cells to conventional treatments such as radiotherapy and chemotherapy, genistein and daidzein are shown to protect non-cancerous cells from the toxic side-effects of conventional cancer treatment [64-66]. One study comparing adverse effects of cancer treatment on treatment with and without soy isoflavone supplementation showed that it is an effective agent to combine with chemotherapy or radiation therapy to improve conventional treatment efficacy and reduce side effects caused by chemotherapeutic drugs and radiation [67]. Children who took the soy isoflavone supplement endured a shorter neutropenia period, fewer infections requiring less antibiotic use, and less severe and shorter duration of oral mucositis [67]. At higher concentrations, genistein's antiviral properties have helped reduce the frequency of viral infections in children, which is essential since cancer patients often experience severe viral infection symptoms because of a suppressed immune system caused by conventional cancer treatment [68].

\section{Quercetin}

Quercetin $(\mathrm{Qu})$, a type of flavonoid, is a phytochemical widely present in foods typically consumed daily. Quercetin is found in many fruits, vegetables, whole grains, and red wine, such as cranberries, apples, and onions [69]. Quercetin is found in the Qu-glucose-conjugate form or Qu-glucoside form in plants [70]. In humans, this form of quercetin is absorbed through enterocytes (absorptive simple columnar epithelial cells in the intestine), hydrolyzed into the Qu-aglycone form. Enterocytic transferases (Beta-Glucuronidase, Sulfotransferase, and catechol-O-methyltransferase) then convert the Qu-aglycone form into glucuronidated, sulfonated, and methylated forms, which are transferred to the liver, where a set of reactions convert these forms into Qu-3-glucuronide 
and Qu-3'-sulfate, which are the main compounds in human plasma originating from quercetin [71]. The conjugated form of quercetin has a higher bioavailability than the unconjugated form in humans. The plasma concentration for the intake of the same amount of the conjugated and unconjugated forms was higher when quercetin was absorbed in the conjugated form [72].

Quercetin has a high potential as a possible complementary treatment for many cancers such as ovarian cancer, prostate cancer, oral squamous cell carcinoma, because of its pro-apoptotic and anti-inflammatory properties [73]. Although quercetin is an effective antioxidant due to its high number of hydroxyl groups and pi orbitals, it can also promote reactive oxygen species [74]. Quercetin's primary oxidation product is semiquinone radical, which is unstable and goes through another reaction to produce the second reaction product, Qu-quinone (QQ), causing DNA and protein damage [74]. However, whether quercetin exerts pro-oxidant or antioxidant effects depends on the levels of intracellular reduced glutathione (GSH) available [75]. In an environment with elevated levels of GSH, Qu-quinone cannot induce cytotoxic effects on DNA and proteins because it reacts with GSH to produce glutathionyl quercetin (GSQ), a stable form of quercetin [75]. DNA and protein damage occurs when there is a low level of GSQ because QQ reacts with protein thiols, leading to apoptosis, as shown in Figure 1 [75]. This property shows the potential of the medicinal use of quercetin for cancer treatment, along the lines of oxidation therapy [76]. At the mRNA level, quercetin can increase p21 and p73 while decreasing the expression of cyclin B1, leading to the halt of the cell cycle at the G2-M checkpoint in esophageal squamous cell carcinoma cell lines [77]. It was shown that even though quercetin treatment was significant, the dose of treatment that had led tumor cell lines to cell cycle arrest had little to no effect on normal, non-transformed cells [78]. In a study where a K562 (myelogenous leukemia) cell line was treated with quercetin, the cells' growth was inhibited, and they were almost completely blocked from proliferation after 24 hours [79]. After 48 hours, caspase 3 , a protein with a central role in apoptosis, activity increased by 3.5 times, confirming that the quercetin treatment led to mechanisms for apoptosis [79]. In the human breast cancer cell line MDA-MB-231, a low dose of the quercetin treatment inhibited proliferation of breast can [80]. In oral squamous cell carcinoma, the epithelial to mesenchymal $\mathrm{t}$ promotes metastasis by increasing primary tumor cell motility and causing the loss of adhesion between the cancerous cells [81]. In addition, matrix metalloproteinase (MMP), an extracellular protease, degrades the extracellular matrix which allows for the transport of cancerous cells into blood and lymph vessels [82]. When oral squamous cell carcinoma lines HN22, SAS, and OSC20 were treated with quercetin, MMP-2 and MMP-9 activation decreased, exhibiting MMP proteases' accumulation due to quercetin [83]. In the OSC20 and SAS cell lines, EMT activating transcription factors Slug and Twist were downregulated in cells treated with quercetin while in the HN22 cell line, Slug was downregulated in quercetin treated cells [83]. Quercetin also exerts its anticancer effects by interfering with the $W n t / \beta$-catenin cell signaling pathway. If not regulated, the $\mathrm{WNT} / \beta$-catenin pathway accumulates $\beta$-catenin in the cell nucleus, which upregulates cyclin D1 and protooncogene c-myc [84]. Quercetin was shown to inhibit Wnt/ $\beta$-catenin cell signaling by downregulating cyclin D1 and survivin in SW480

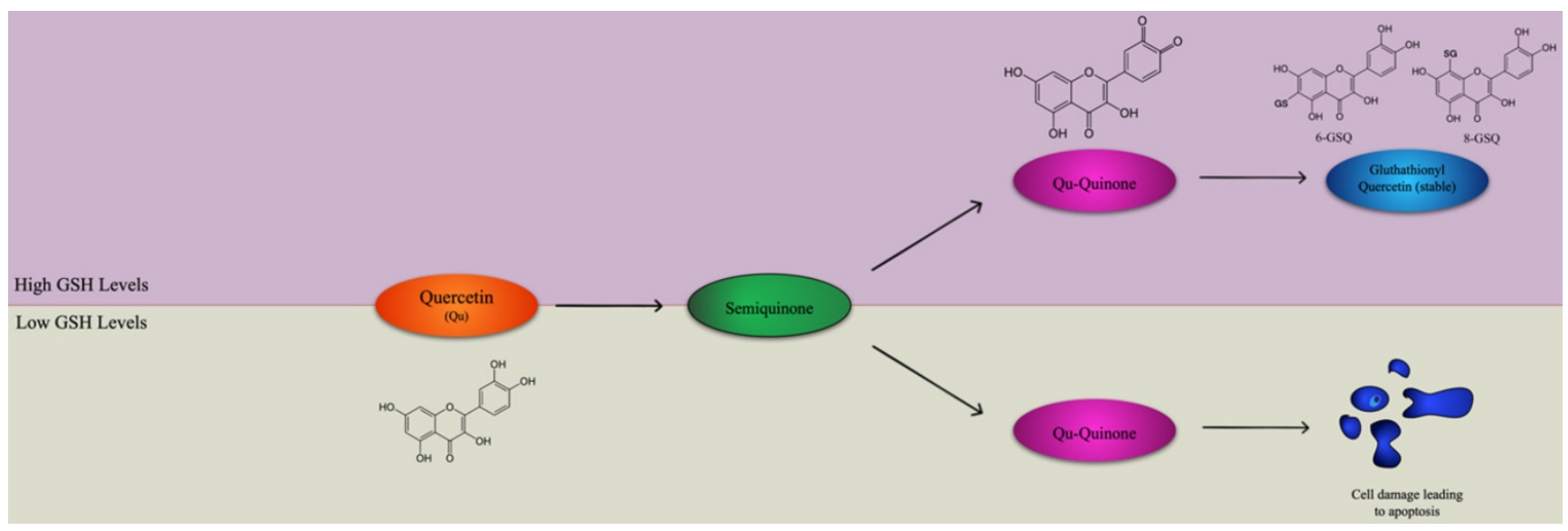

Figure 1. Quercetin applies either antioxidant or pro-oxidant effects depending on the level of intracellular reduced glutathione (GSH). Quercetin and $\mathrm{H} 2 \mathrm{O} 2$ react to form a semiquinone radical which is oxidized to Quercetin-Quinone (Qu-Quinone). In greater levels of GSH, QQ reacts with GSH to form the stable glutathionyl quercetin (GSQ) forms of 8-GSQ and 6-GSQ. However, when there are lower levels of GSH, Qu-Quinone reacts with protein thiols, resulting in cell damage leading to apoptosis. Adapted from [75]. 
colon cancer cells [85].

Although quercetin has been shown to be effective at chemoprevention, its activity is mainly exclusive towards transformed cell lines rather than indiscriminately inducing apoptosis and cell cycle arrest in tumors and standard cell lines [78]. Quercetin can exert apoptotic potential on leukemic cell lines without causing apoptosis in peripheral blood mononuclear cells [86]. Gastrointestinal mucositis, the ulceration and inflammation of the mucous lining of the gastrointestinal tract, occurs in up to $40 \%$ of patients going through chemotherapy [87]. One study compared the effect of quercetin treatment on rats treated with methotrexate, a chemotherapeutic drug that is known to induce gastrointestinal mucositis [88]. Rats treated with quercetin experienced decreased mucosal inflammation, while damage to the intestinal mucous lining was reversed [88]. Even though quercetin induces apoptosis in many tumor cell lines, caspase- 3 protein levels were lower in the rats treated with quercetin, demonstrating the anti-apoptotic effects quercetin exerted in intestinal cells during repair of the intestinal mucous lining [88]. Chemotherapy-induced fatigue is one of the most common adverse effects of chemotherapy and is typically caused by the chemotherapeutic drug, 5-FU. A study conducted on two groups of mice treated with 5-FU showed that the group of mice treated with quercetin initially had low levels of activity following 5-FU treatment but returned to normal activity levels 8 days after 5-FU treatment. In contrast, mice without quercetin treatment returned to normal activity levels 14 days after 5-FU treatment [89]. Typically, the 5-FU treatment causes an increase in Monocyte Chemoattractant Protein-1 (MCP-1) inflammatory cytokine in the plasma, which is associated with fatigue and is a marker of anemia [90]. Quercetin treatment effectively crippled the response of MCP-1, as there was no change in MCP-1 levels after 5-FU treatment in mice created with quercetin compared to elevated levels of MCP-1 after 5-FU treatment in the group of mice without quercetin treatment [89]. This can be attributed to the decrease in MCP-1 promoter gene expression and decrease in the activation of the Nuclear Factor Kappa B (NF-kB) pathway (key mediator in inflammatory response) by quercetin [91].

\section{Curcumin}

Curcumin, a type of polyphenol, is a pigment found mainly in the rhizome of the plant Curcuma longa (Turmeric), but can also be found in Curcuma aromatica, Curcuma Mangga, Zingiber cassamunar, Etlingera elatior, Costus speciosus, Curcuma xanthorrhiza, Curcuma phaeocaulis, and Curcuma Zedoaria [92]. Turmeric has been used in ancient Asian medicine for thousands of years to treat various inflammatory conditions and is a common spice used in Indian cooking [93]. Although curcumin has poor bioavailability in humans due to its low solubility in water, many factors can increase the absorption of the phytochemical [94]. Oral intake of the combination of curcumin and piperine (natural alkaloid of black pepper) significantly increased bioavailability and absorption of curcumin due to the inhibition of glucuronidation by piperine [95]. The combination of curcumin and lecithin has been shown to improve gastrointestinal absorption of poorly water-soluble phytochemicals such as curcumin due to the amphipathic property of the phospholipids in lecithin [96]. Nanoparticle drug delivery is one of the most promising methods for increasing drug bioavailability. Curcumin taken along with hydrophilic nanoparticles can increase oral absorption by 46 times due to increased water-solubility of the combination compared to pure curcumin $[97,98]$.

Many studies have illuminated on curcumin's chemopreventive effects due to its anti-inflammatory and antioxidant properties. One of the first studies on curcumin and cancer investigated curcumin's effect on cancerous lesions' on skin surface [99]. In the clinical trial, $90 \%$ of patients experienced a decrease in the lesions' swelling, while $10 \%$ experienced a reduction in lesion size with a $1 \%$ curcumin ointment application [99]. Curcumin decreased lipid peroxidation and restored the hepatic glutathione antioxidant defense, leading to the prevention of hepatic cancer in Wistar rats [100]. In a clinical trial where $2 \mathrm{~g}$ of Meriva (contains curcumin phytosome complex) and $100 \mathrm{mg} / \mathrm{m}^{2}$ of gemcitabine (chemotherapeutic drug) were administered to 44 pancreatic cancer patients, the patients had an overall survival of 10.2 months compared to 5.7 months when treated with only gemcitabine [101]. Curcumin typically accumulates in the colon's mucous lining compared to other areas of the body, hinting at curcumin's vital role colorectal cancer [102]. In a clinical trial for colorectal cancer, oral intake of $3.6 \mathrm{~g}$ of curcumin decreased prostaglandin E2 (a bioactive lipid that exerts many cancer and inflammatoryrelated effects) production in blood after 1 hour of administration [103]. Another study done over 126 colorectal cancer patients showed a significant increase in tumor cell apoptosis after 1,080 mg of curcumin was given daily for 10-30 days, which can be attributed to the upregulation of p53 and increase in Bax/Bcl-2 ratio in the tumor tissues [104]. Bcl-2 and Bax are the major proteins of the Bcl-2 family with roles in tumor progression [105]. Bax is a proapoptotic protein that causes apoptosis by increasing mitochondrial membrane permeability, releasing 
cytochrome c into the cytosol [105]. On the other side, Bcl-2 is an anti-apoptotic protein and inhibits Bax activity [105]. Therefore, the ratio of Bax and Bcl-2 proteins present determines the fate of tumor progression.

In many clinical trials and studies, curcumin has been shown to suppress cancer cell invasion through growth factor, cytokine, and adhesion molecule regulation [106]. One mechanism of curcmin's antitumor property is the inhibition of the NF- $\mathrm{kB}$ pathway, which causes the prevention of MMP, inflammatory cytokines, and metastatic enzyme expression [107]. Curcumin prevents the degradation of IкBa, which inhibits the NF-kB transcription factor [109]. Genes associated with tumor formation are not expressed since the p65 subunit of NF-KB does not transport to the nucleus [109]. This inhibitory process leads to apoptosis and decreased cell proliferation of various tumor cell lines [109]. Curcumin plays a significant role in the downregulation of the $\mathrm{WNT} / \beta$ catenin pathway to prevent cancer and tumor growth, as it has been shown to promote apoptosis and inhibit tumor cell migration in hepatocellular carcinoma cells by decreasing expression of glypican-3, which can inhibit c-myc, cyclin D1, VEGF, and $\beta$-catenin expression, which in turn inhibited $\mathrm{WNT} / \beta$-catenin signaling [110-113]. Curcumin can promote apoptosis and inhibit gastric carcinoma cell growth through suppression of Wnt3a, LRP6, phospho-LRP6 at Ser1490, $\beta$-catenin, phospho- $\beta$-catenin at Ser675, $\mathrm{C}$-myc, and survivin proteins involved in the
WNT/ $\beta$-catenin pathway [114]. Curcumin can also exert its anticancer effects through the modulation of the JAK/STAT signaling pathway. Once cytokines bind to cytokine receptors, the receptors are dimerized, phosphorylating JAK (Janus Kinase), which in turn, phosphorylates the cytosolic domain of the cytokine receptor [115]. Eventually, the STAT protein is phosphorylated, forming a dimer, which transports to the nucleus and acts as a transcription factor to promote various cytokine-mediated immune responses [115]. Misregulation of the JAK/STAT cell signaling pathway can lead to EMT and tumor growth [116]. Curcumin can inhibit proliferation and promote apoptosis in retinoblastoma cells by reducing STAT1, STAT3, and JAK1 phosphorylation, suppressing the JAK/STAT pathway [117]. Curcumin was also able to inhibit angiogenesis in laryngeal squamous cell carcinoma cells by inhibiting JAK2 and STAT3 phosphorylation, preventing VEGF and MMP-2 [118]. The PI3K/Akt pathway plays a large role in promoting cell growth, proliferation, and metabolism [119]. Growth factors, such as EGF and VEGF, bind to RTKs, forming an active complex through phosphorylation [117]. Then PIP2 converts to PIP3 through an intermediate PI3K, activating AKT after phosphorylation of its serine and threonine groups [119]. The AKT protein promotes cell growth and proliferation through phosphorylation of mTOR and NF-kB, inactivation of Glycogen synthase kinase three beta (GSK3 $\beta$ ) via phosphorylation, and blocking of apoptotic mechanisms through the

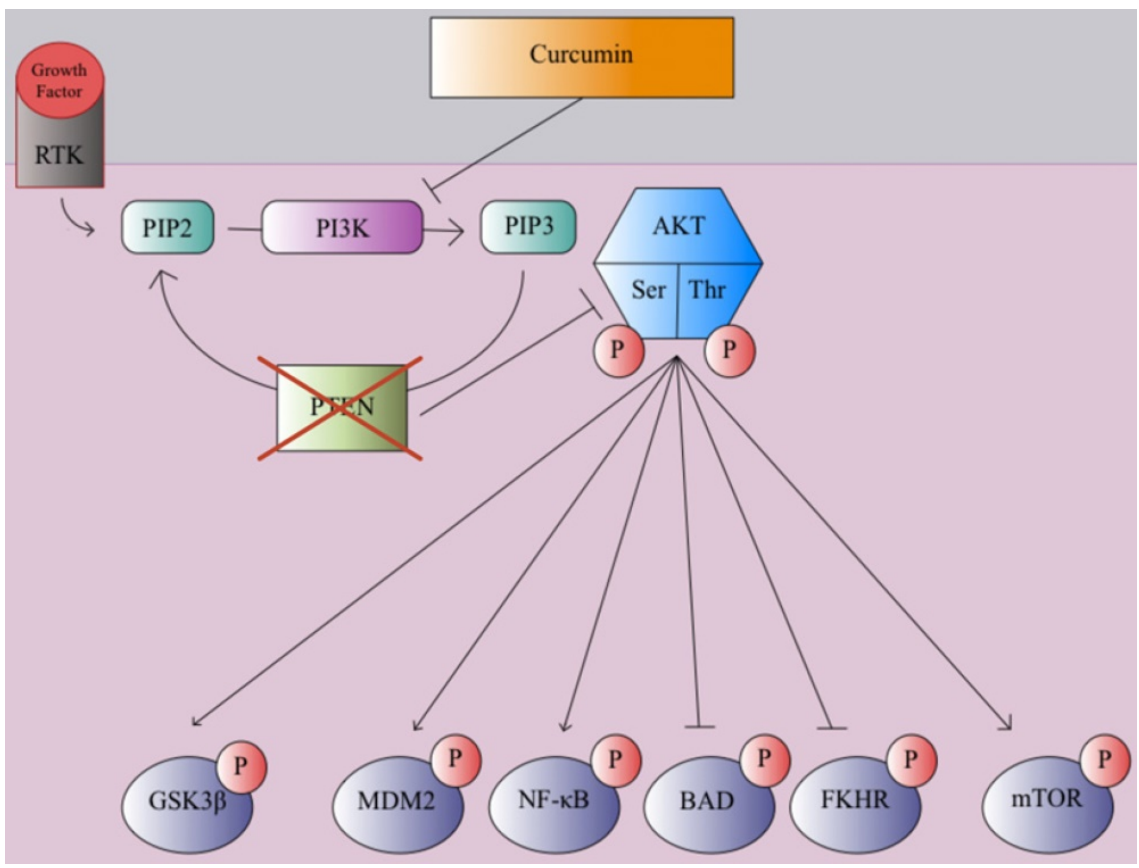

Figure 2. PTEN, a tumor suppressor and regulator of the PI3K/AKT pathway is commonly disrupted and unable to inhibit AKT phosphorylation during the early stages of cancer progression. Curcumin inhibits PI3K and blocks AKT phosphorylation which in turn blocks mTOR and MDM2 phosphorylation while preventing inactivation of GSK3 $\beta$ via phosphorylation and the suppression of pro-apoptotic and antiproliferative proteins, reducing cell growth, proliferation, and motility [121-123]. 
phosphorylation of NF-KB, FKHR, BAD, and MDM2 [119]. Overexpression of the PI3K/Akt pathway can lead to cancer progression, as AKT kinase regulator PTEN is typically disrupted in many cancers [120]. Phytochemicals such as curcumin exert antitumor effects on breast cancer cells through inhibition of PI3K phosphorylation, in turn, inhibiting mTOR and NF- $\mathrm{KB}$ phosphorylation and avoiding inactivation of GSK3 $\beta$ as shown in Figure 2 [121-123].

In addition to the antitumor, anti-proliferative, and pro-apoptotic effects curcumin as on various cancer cell lines, curcumin has shown to have a preventative effect against chemotherapy-induced side effects [124]. Chemotherapy-induced gastrointestinal damage can lead to the destruction of the intestine's mucous lining, causing higher vulnerability to viral infections, anorexia, nausea, vomiting, and fever; it can also be a dose-limiting factor reducing the efficacy of chemotherapy cancer treatment [124]. In one study, 60 Wistar rats were divided into three groups, one treated with 5-FU only, another treated with 5-FU and curcumin, and the last group as a control [125]. The 5-FU only treated rats experienced a destructed mucous lining, villi loss, infiltration of lymphocytes, and the death of the small intestine [125]. When curcumin was administered along with 5-FU, the mucous lining was not as infiltrated with lymphocytes and was thicker with less destruction and villi loss [125]. Curcumin can also make various tumor cell lines more sensitive to chemotherapeutic drugs such as cisplatin but protects non-transformed cells against cisplatin-induced neurotoxicity [125]. In one study, curcumin reduced cisplatin-induced DNA damage in non-transformed PC12 cells [126]. In a more recent study, curcumin reduced up to $50 \%$ of cisplatin's toxic inhibitory effect on neurite outgrowth in Wistar rats [127]. Myelosuppression, the suppression, and decrease in bone marrow activity leading to a reduction in $\mathrm{RBC}$ production are common side effects of chemotherapy, especially the chemotherapeutic drug carboplatin [128]. In a study conducted with a tumor-bearing mouse model, mice's survival rate was significantly higher when administered a combination of curcumin and carboplatin compared to only carboplatin over 20 days [128]. The group of mice that were administered a combination of curcumin and carboplatin experienced improved bone marrow damage and an increase in white blood cell and platelet counts to levels before carboplatin treatment, illuminating on curcumin's ability to promote the repair of carboplatin-induced myelosuppression [128].

\section{Catechins}

Catechins, a type of polyphenol, are a group of phytochemicals present in fluids such as green tea produced from the leaves of the Camellia sinensis plant [130]. The primary catechin in green tea is epigallocatechin-3-gallate (EGCG), and consequently, the most thoroughly studied catechin [130]. Other catechins present in green tea include epigallocatechin (EGC), epicatechin (EC), epicatechin-3-gallate (ECG), caffeic acid (CA), gallic acid (GA), gallocatechin (GC), catechin (C), and catechin gallate (CG) [130]. Transferases catechol-O-methyltransferase, UDPglucuronosyltransferases, and sulphotransferases conjugate a large fraction of tea catechins absorbed by the liver and small intestine, while microbes degrade the rest of the catechins into flavonoid rings after passing through the colon [131]. These conjugated forms can circulate in plasma and perform biological functions after being distributed to the necessary tissues [131]. Catechins are typically transported into cells through passive diffusion, as there are currently no known receptors on the intestinal epithelium that are known to assist in the transport of tea catechins into cells to perform biological functions [132]. Multidrug-resistance associated protein efflux pumps such as P-glycoprotein pump out absorbed catechins into the intestinal space, limiting the bioavailability of tea catechins [133]. In vitro studies have shown that around 1-100 $\mu \mathrm{mol} / \mathrm{L}$ of ECGC is required to exert significant anticancer and anti-inflammatory effects, but due to the instability of EGCG in the GI tract and poor absorption, the plasma in humans had a low EGCG micromolar range [134]. Nanoparticle drug delivery is the most promising method of increasing the bioavailability of catechins such as EGCG. Nano-carriers using carbohydrates, proteins, and lipids for tea catechins can improve solubility, increase permeability in the intestine to catechins, and decrease catechins' degradation in the small intestinal lumen $[135,136]$. Modification of catechins' molecular structure, such as a peracetylated version of EGCG (AcEGCG), has been shown to increase bioavailability and stability in various internal conditions [137]. Dextran-Catechin, a chemically conjugated catechin form, was more effective in counteracting neuroblastoma and drug-resistant tumor cells than unconjugated catechin [138]. The synergistic combination of catechins and other chemotherapeutic drugs or phytochemicals (piperine, genistein, curcumin) has also been shown to increase the bioavailability and efficacy of dietary catechins in cancer treatment [139].

Tea catechins, most notably EGCG, have been proven to combat many cancers such as neuroblastoma, breast cancer, prostate cancer, and colorectal cancer $[140,141]$. One study investigating the effects of EGCG on the cell growth of breast cancer 
cell lines MDA-MB-231 and MCF-7 found a dose of 100um of EGCG to decrease the cell viability index of MCF-7 and MDA-MB-231 by over 50\% in 24 hours, suggesting the significant inhibition of MDA-MB-231 and MCF-7 cell line growth [142]. A diet including Polyphenon E, a green tea polyphenol extract with a high concentration of catechins due to a water-based extraction method, decreased the amount of Benzo[a]pyrene-induced lung tumors in AJ inbred mice $[143,144]$. In a study investigating the effect of tea catechins on the SW-480 and HCT-116 colorectal cancer cell lines, phytochemicals in the galloylated catechin group exerted the most powerful anti-proliferative effects. 100um of EGCG, ECG, GCG, and CG inhibited HCT-116 cell growth by $98.4 \%$, $20.3 \%, 79.2 \%$, and $20.2 \%$, respectively [145]. Oral ingestion of Polyphenon E led to a significant decrease in the development of tumors in Tyrosine hydroxylase-MYCN transgenic mice, as half of the Polyphenon E treated mice were tumor-free after eight months, compared to the control group [146]. EGCG treatment inhibited invasion and migration of Nasopharyngeal Carcinoma (NPC) cells, but only exerted a minor anti-proliferative effect on the NP460hTert immortalized NPC cell line [147].

Many cases have shown catechins' efficacy in inhibiting tumor cell proliferation, invasion, migration, and growth. One of the pathways through which tea catechins exert their antitumor effects is the $W n t / \beta$-Catenin pathway. As previously discussed, the Wnt/ $\beta$-Catenin pathway's dysregulation leads to tumor progression [84]. Typically, without the Wnt signal, a complex involving GSK3 $\beta$, adenomatous polyposis coli, and axin phosphorylates $\beta$-catenin leads to the degradation of $\beta$-catenin by a proteasome [148]. This process prevents $\beta$-catenin from transporting to the nucleus, leading the upregulation of cyclin D1 and protooncogene c-myc [84]. In the presence of the Wnt signal, membrane receptors activate and degrade GSK3 $\beta$, causing $\beta$-catenin to accumulate in the nucleus and influence transcription [149]. EGCG can inhibit GSK3 $\beta$ degradation and phosphorylation while promoting GSK3 $\beta$ expression, leading to a decrease in the amount of $\beta$-catenin in cancer cells [150]. EGCG was able to reduce $\beta$-catenin transcription and mRNA levels in a keratin-forming tumor cell line while increasing the breakdown and ubiquitylation $\beta$-catenin [150]. EGCG is also able to exert its anticancer effects by interfering with the JAK/STAT signaling pathway. As previously mentioned, the JAK/STAT pathway's dysregulation can lead to EMT and tumor cell proliferation. In oral cancer cells, EGCG reduced phosphorylation of serine and tyrosine of the STAT1 activator and inhibited JAK1 and JAK2 phosphorylation [151]. EGCG inhibited $\mathrm{c}-\mathrm{Myb}$ expression, which in turn reduced NF-kB and STAT3 signaling, eliminating the proliferation and invasion of ovarian cancer cells [152]. Inhibition of c-Myb also reduced the resistance of ovarian cancer cells against the chemotherapeutic drug cisplatin [152]. EZH2 is a protein that mediates the trimethylation of the 27th amino acid in histone 3 (H3K27), causing the suppression of the tissue inhibitor of MMP3 (TIMP3), leading to the degradation of the ECM, allowing cancer cells to transport through blood and lymph vessels [153]. EGCG inhibited the trimethylation of H3K27 by $\mathrm{EZH} 2$, preventing the potential for prostate cancer cell invasion and migration [154]. Signaling of transforming growth factor- $\beta$ (TGF $\beta$ ) is regulated by SMAD proteins, type 1 and 2 receptors, and TGF $\beta$ ligands [155]. Misregulation of the TGF $\beta$ signaling pathway can lead to cancer progression through SMAD2/3 protein expression, promoting the expression of Snail and Slug transcription factors that induce EMT [156]. EGCG was able to repress EMT and the invasive and migratory activity of the 8505C lung cancer cell line by inhibiting the phosphorylation of SMAD2/3 and downregulation of epithelial cadherin (E-cadherin). This adhesion molecule prevents the migratory activity of cancer cells [157]. miR-485, a microRNA with tumor-suppressing properties, targets CD44, a glycoprotein involved in cell proliferation, migration, and angiogenesis. In A549 cisplatin-resistant cancer cells, CD44 was overexpressed while miR-485 was suppressed, but EGCG lowered CD44 levels by amplifying CD44 suppression by miR-485 [158].

Tea catechins have also shown to have a protective effect against the effect of chemotherapy drugs on non-transformed cells in addition to their anticancer properties. Irinotecan (IT) is a chemotherapeutic drug with dose-limiting toxicity because of its severe effects on the small intestine [159]. Irinotecan treatment caused high levels of inflammation and lipid peroxidation due to myeloperoxidase (MPO) activity, as well as a drop in GSH concentration of the ileum of mice and an increase in the oxidized version of GSH, glutathione disulfide (GSSG) [160,161]. Low GSH levels lead to the activation of inflammatory pathways such as the NF- $\mathrm{kB}$ signaling pathway and an increase in MPO activity, leading to damage of non-transformed tissue [161]. EGCG treatment before UV-radiation treatment in mice inhibited MPO activity and an increase in glutathione sulfide, lowering the GSH:GSSG ratio [161]. EGCG was also able to inhibit leukocyte infiltration in IT-treated mice [162]. However, more studies are needed on the correlation between green tea polyphenols and an increase in GSH concentration 
in the small intestine after irinotecan treatment. Doxorubicin (DOX), a chemotherapeutic drug in the anthracycline family, is effective against many types of cancers such as leukemia and breast cancer [163]. However, doxorubicin can exert its gonadotoxic effects on human ovarian tissue, causing the loss of reproductive function in female patients [164]. When EGCG was given in combination with doxorubicin, doxorubicin-induced inflammation in ovarian tissue was significantly reduced [165]. This can be attributed to the inhibitory effect on doxorubicin-induced cytokine, interleukin, and MMP expression by EGCG [165].

\section{Hesperidin}

Hesperidin, one of the most consumed flavonoids, is a phytochemical widely present in citrus fruits such as orange, tangerine, lemon, lime, and grapefruit, as well as herbs such as peppermint [166]. Hesperidin is converted to its aglycone form, hesperidin, upon consumption [167]. Hesperidin, a rutinoside, is hydrolyzed by the gut flora and then is absorbed in the colon [168]. The peak plasma levels of hesperidin in relation to the amount of hesperidin ingested are similar to other flavonoids such as quercetin, but the absorption of hesperidin is lower than that of genistein, daidzein, and other isoflavones [167]. Due to the gut microflora enzymes cleaving the C-ring from hesperidin, studies investigating urinary recovery determined hesperidin's low bioavailability [168]. To reap effects from hesperidin, citrus foods must be consumed regularly because of the high urinary elimination rate of hesperidin. After 24 hours of hesperidin intake, $98 \%$ of the metabolites were eliminated in the urine, and hesperidin was not present in the plasma [167]. Further studies are required to investigate methods to increase the absorption and bioavailability of hesperidin and other rutinosides.

Many studies indicate that hesperidin possesses high potential as a chemopreventive treatment for skin and colon cancer treatment due to its pro-apoptotic and anti-proliferative properties [169]. Hesperidin was able to induce cell death of the HepG2 liver cancer cell line in a dose-response manner [170]. In one study which investigated the effect of orange juice, which contains a large amount of hesperidin, on colon cancer, oral intake of orange juice reduced the extent of tumor growth in rats by $22 \%$ [171]. A greater-strength orange juice was able to inhibit mammary cancer progression in rats [172]. One study investigated the effect of hesperidin (aglycone form of hesperidin) on rats with 1,2-dimethylhydrazine (DMH) induced colon cancer [173]. Rats in the control group (DMH administration without hesperidin) experienced an increased presence of aberrant crypt foci (ACF; a precursor to colorectal cancer) and tumor growth, as well as a decrease in glutathione peroxidase and glutathione S-transferase, a phase II detoxification enzyme [175-177]. DMH-induced colon cancer rats experienced the most significant decrease in tumor and ACF formation when treated with a hesperidin dose of $20 \mathrm{mg} / \mathrm{kg}$ [173]. Hesperidin treatment led to the suppression of lung carcinoma, neoplastic lesions, oxidative stress, and lipid peroxidation caused by benzo(a)pyrene in Swiss albino mice [178]. Hesperetin-7-O-acetate, the acetylated version of hesperidin, significantly decreased cell viability and increased caspase- 3 and caspase- 9 activity of the A-494 renal carcinoma cell line [179]. When the PC3 prostate cancer cell line was exposed to hesperidin, the cell viability decreased by $80 \% 48$ hours after treatment, indicating the anti-proliferative effect of hesperidin [180].

One mechanism of Hesperidin's antitumor property is the inhibition of the specificity protein 1 (Sp1) transcription factor. The Sp1 transcription factor can regulate cyclin D1, survivin, Mcl-1, p27, and p21 gene expression, which are involved in cell growth, apoptosis, metabolism, and angiogenesis [181]. Elevated levels of Sp1 have been associated with many cancers, indicating that Sp1 can potentially serve as a molecular target for cancer treatment and chemoprevention [182]. Hesperidin's inhibitory effect on Sp1 promoted apoptosis in MSTO-211H, a human mesothelioma cell line [183]. It upregulated Bax expression while downregulating Bcl-2 expression, disrupting tumor progression in the SNU-C4 human colon cancer line [184]. It has been able to exert its anticancer effects through inhibition of the NF- $\mathrm{kB}$ signaling pathway and activator protein 1 (AP-1), which in turn inhibits MMP-9 expression in the HepG2 liver cancer cell line [185]. Hesperidin exerted pro-apoptotic effects by upregulating p53 and caspase-3 levels while inducing DNA fragmentation in the MCF-7 breast cancer cell line [186]. It also exerts its pro-apoptotic effects by inhibiting the TGF $\beta$ signaling pathway by blocking the phosphorylation of SMAD3, thus leading to a reduction in cancer cell proliferation and metastasis [187]. Hesperidin inhibited cell migration and tube formation in human umbilical vein endothelial cells due to the inhibition of the PI3K/Akt signaling pathway by hesperidin, blocking mTOR phosphorylation [188].

Although many studies have shown hesperidin to effectively block cell growth, proliferation, and metastasis promoting pathways in various cancer cell lines, hesperidin has a protective effect against chemotherapy-induced side effects. As discussed 
previously, cisplatin, a common chemotherapeutic drug, causes many adverse effects in patients such as gastrointestinal, neutrality, and CINV. In one study investigating the effect of hesperidin on cisplatin-induced eye toxicity in rats, hesperidin treatment of $50 \mathrm{mg}$ per $\mathrm{kg}$ of body weight prevented retina and cornea damage, a drop in GSH levels, an increase in thiobarbituric acid reactive substances, and a decrease in antioxidant activity [189]. Cisplatin-induced liver toxicity was alleviated by hesperidin without a decrease in anticancer activity in rats [190]. Diarrhea is one of the most common adverse effects of chemotherapy and occurs in up to $80 \%$ of patients, while severe diarrhea occurs in more than $30 \%$ of patients, resulting in malnutrition and low quality of life [191]. Hesperidin can reduce intestinal inflammation by blocking cytokine release, inhibiting NF-kB expression, and reducing inflammatory cell infiltration in an animal model with irinotecan-induced diarrhea [192].

\section{Conclusions and Outlook}

Due to the prevalence of cancer incidence throughout the world, effective means of attenuating various cancers are of great interest. Although conventional chemotherapy is effective against many cancer cell lines, its non-specificity can result in various dose-limiting side effects. Chemoprevention by dietary phytochemicals is a relatively non-invasive targeted approach with predictive and preventative attributes [193, 194]. In addition, phytochemical

\section{References}

1. Siegel RL, Miller KD, Jemal A. Cancer statistics. CA Cancer J Clin. 2020; 70(1):7-30.

2. Heron M. Deaths: Leading Causes for 2017. National Vital Statistics Reports 2019; 68(6):1-76.

3. Loeb LA, Harris CC. Advances in chemical carcinogenesis: a historical review and prospective. Cancer Res. 2008; 68(17):6863-6872.

4. Barcellos-Hoff MH, Lyden D, Wang TC. The evolution of the cancer niche during multistage carcinogenesis. Nat Rev Cancer. 2013;13(7):511-518.

5. Ashkenazi R, Gentry SN, Jackson TL. Pathways to tumorigenesis-modeling mutation acquisition in stem cells and their progeny. Neoplasia. 2008;10(11):1170-82.

6. Royston KJ, Tollefsbol TO. The epigenetic impact of cruciferous vegetables on cancer prevention. Current pharmacology reports. 2015;1(1):46-51.

7. Steward WP, Brown K. Cancer chemoprevention: a rapidly evolving field. British journal of cancer. 2013; 109(1):1-7.

8. Wang H, Oo Khor T, Shu L, Su ZY, Fuentes F, Lee JH, Tony Kong AN. Plants vs. cancer: a review on natural phytochemicals in preventing and treating cancers and their druggability. Anti-Cancer Agents in Medicinal Chemistry (Formerly Current Medicinal Chemistry-Anti-Cancer Agents). 2012;12(10):1281-305

9. Leitzmann C. Characteristics and Health Benefits of Phytochemicals. Complementary Medicine Research. 2016;23(2):69-74. application has shown to be relatively cost-effective and more economically attractive in relation to conventional treatments. [25] In many clinical trials, phytochemical application inhibited various cell signaling pathways associated with cancer cell progression and protected normal cells against chemotherapy-induced damage. Nano Drug Delivery, an emerging technology, is a promising method for increasing the absorption and bioavailability of many dietary phytochemicals. Specific combinations for select phytochemicals such as piperine and curcumin. Despite the many advantages of phytochemicals reviewed in this paper, much of the evidence is based on early-stage research on mice. Additional clinical trials on humans have the potential to fill the gaps in phytochemical research and significantly increase our understanding of their potency, toxicities, efficacy, and drug-drug interactions.

This review has attempted to provide a summary of current research on phytochemical application as a complementary approach to chemoprevention. Understanding phytochemicals' effect on cancerous cells and surrounding nontransformed cells will allow for a more cost-effective, non-invasive, and targeted approach to cancer treatment in the future.

\section{Competing Interests}

The authors have declared that no competing interest exists.
10. Molyneux RJ, Lee ST, Gardner DR, Panter KE, James LF. Phytochemicals: the good, the bad and the ugly?. Phytochemistry. 2007;68(22-24):2973-85.

11. Collins AR, Azqueta A, Langie SA. Effects of micronutrients on DNA repair. European journal of nutrition. 2012;51(3):261-79.

12. Royston KJ, Tollefsbol TO. The epigenetic impact of cruciferous vegetables on cancer prevention. Current pharmacology reports. 2015;1(1):46-51.

13. Luis Espinoza J, Takami A, Trung LQ, Nakao S. Ataxia-telangiectasia mutated kinase-mediated upregulation of NKG 2 D ligands on leukemia cells by resveratrol results in enhanced natural killer cell susceptibility. Cancer science. 2013;104(6):657-62.

14. Sapienza C, Issa JP. Diet, nutrition, and cancer epigenetics. Annual review of nutrition. 2016;36

15. Kreidieh FY, Moukadem HA, El Saghir NS. Overview, prevention and management of chemotherapy extravasation. World J Clin Oncol. 2016;7(1):87-97.

16. Abbas Z, Rehman S. An overview of cancer treatment modalities. Neoplasm. 2018 Sep 19;1:139-57.

17. Agarwal MB. Is cancer chemotherapy dying? Asian J Transfus Sci. 2016 May;10(Suppl 1):S1-7.

18. Mansoori B, Mohammadi A, Davudian S, Shirjang S, Baradaran B. The different mechanisms of cancer drug resistance: a brief review. Advanced pharmaceutical bulletin. 2017;7(3):339.

19. Rizeq B, Gupta I, Ilesanmi J, AlSafran M, Rahman MM, Ouhtit A. The power of phytochemicals combination in cancer chemoprevention. Journal of Cancer. 2020;11(15):4521. 
20. Dinu M, Abbate R, Gensini GF, Casini A, Sofi F. Vegetarian, vegan diets and multiple health outcomes: a systematic review with meta-analysis of observational studies. Critical reviews in food science and nutrition. 2017;57(17):3640-9.

21. Anand P, Kunnumakara AB, Sundaram C, Harikumar KB, Tharakan ST, Lai OS, Sung B, Aggarwal BB. Cancer is a preventable disease that requires major lifestyle changes. Pharmaceutical research. 2008;25(9):2097-116.

22. Kucera R, Pecen L, Topolcan O, Dahal AR, Costigliola V, Giordano FA, Golubnitschaja O. Prostate cancer management: long-term beliefs, epidemic developments in the early twenty-first century and 3PM dimensional solutions. EPMA J. 2020;11(3):399-418.

23. Mollakhalili Meybodi N, Mortazavian AM, Bahadori Monfared A, Sohrabvandi S, Aghaei Meybodi F. Phytochemicals in cancer prevention: a review of the evidence. Iranian Journal of Cancer Prevention. 2017;10(1)

24. Cruz-Correa M, Shoskes DA, Sanchez P, Zhao R, Hylind LM, Wexner SD, Giardiello FM. Combination treatment with curcumin and quercetin of adenomas in familial adenomatous polyposis. Clinical Gastroenterology and Hepatology. 2006;4(8):1035-8

25. Samec M, Liskova A, Koklesova L, Samuel SM, Zhai K, Buhrmann C, Varghese E, Abotaleb M, Qaradakhi T, Zulli A, Kello M. Flavonoids against the Warburg phenotype-Concepts of predictive, preventive and personalised medicine to cut the Gordian knot of cancer cell metabolism. EPMA Journal. 2020:1-22.

26. Larasati YA, Yoneda-Kato N, Nakamae I, Yokoyama T, Meiyanto E, Kato JY. Curcumin targets multiple enzymes involved in the ROS metabolic pathway to suppress tumor cell growth. Scientific reports. 2018;8(1):1-3

27. Goldsmith CD, Bond DR, Jankowski H, Weidenhofer J, Stathopoulos CE, Roach PD, Scarlett CJ. The olive biophenols oleuropein and hydroxytyrosol selectively reduce proliferation, influence the cell cycle, and induce apoptosis in pancreatic cancer cells. International journal of molecular sciences. 2018;19(7):1937.

28. Tacyildiz N, Ozyoruk D, Yavuz G, Unal E, Dincaslan H, Dogu F, Sahin K, Kucuk O. Soy isoflavones ameliorate the adverse effects of chemotherapy in children. Nutrition and cancer. 2010;62(7):1001-5.

29. Navari RM. The safety of antiemetic medications for the prevention of chemotherapy-induced nausea and vomiting. Expert opinion on drug safety. 2016;15(3):343-56.

30. Rapoport BL. Delayed chemotherapy-induced nausea and vomiting: pathogenesis, incidence, and current management. Frontiers in pharmacology. 2017;8:19.

31. Aapro M. 5-HT3-receptor antagonists in the management of nausea and vomiting in cancer and cancer treatment. Oncology. 2005;69(2):97-109.

32. Garcia-Recio S, Gascón P. Biological and Pharmacological Aspects of the NK1-Receptor. Biomed Res Int. 2015;2015:495704.

33. Datar P, Srivastava S, Coutinho E, Govil G. Substance P: structure, function, and therapeutics. Current topics in medicinal chemistry. 2004;4(1):75-103.

34. Hesketh PJ. Chemotherapy-induced nausea and vomiting. New England Journal of Medicine. 2008;358(23):2482-94.

35. Weber GF. Molecular therapies of cancer. Cincinnati, USA: Springer; 2015

36. Peters GJ, Van der Wilt CL, Van Moorsel CJ, Kroep JR, Bergman AM, Ackland $\mathrm{SP}$. Basis for effective combination cancer chemotherapy with antimetabolites. Pharmacology \& therapeutics. 2000;87(2-3):227-53.

37. Ha JH, Hwang DY, Yu J, Park DH, Ryu SH. Onset of manic episode during chemotherapy with 5-fluorouracil. Psychiatry Investigation. 2011;8(1):71.

38. Rogers JE, Dasari A, Eng C. The Treatment of Colorectal Cancer During Pregnancy: Cytotoxic Chemotherapy and Targeted Therapy Challenges. Oncologist. 2016;21(5):563-70

39. Kanduri J, More LA, Godishala A, Asnani A. Fluoropyrimidine-associated cardiotoxicity. Cardiol Clin. 2019;37(4):399-405.

40. Shiga T, Hiraide M. Cardiotoxicities of 5-Fluorouracil and other fluoropyrimidines. Current treatment options in oncology. 2020;21(4):1-21.

41. Sara JD, Kaur J, Khodadadi R, Rehman M, Lobo R, Chakrabarti S, Herrmann J, Lerman A, Grothey A. 5-fluorouracil and cardiotoxicity: a review. Therapeutic advances in medical oncology. 2018;10:1758835918780140.

42. Song JK. Coronary artery vasospasm. Korean circulation journal. 2018:48(9):767.

43. Yuan C, Parekh H, Allegra C, George TJ, Starr JS. 5-FU induced cardiotoxicity: case series and review of the literature. Cardio-Oncology. 2019;5(1):1-7.

44. Yu J, Bi X, Yu B, Chen D. Isoflavones: anti-inflammatory benefit and possible caveats. Nutrients. 2016;8(6):361.

45. Křížová L, Dadáková K, Kašparovská J, Kašparovský T. Isoflavones. Molecules. 2019;24(6):1076.

46. Ganai AA, Farooqi H. Bioactivity of genistein: a review of in vitro and in vivo studies. Biomedicine \& pharmacotherapy. 2015;76:30-8

47. Ardito F, Di Gioia G, Pellegrino MR, Muzio LL. Genistein as a Potential Anticancer Agent Against Head and Neck Squamous Cell Carcinoma. Current topics in medicinal chemistry. 2018;18(3):174-81.

48. Varinska L, Gal P, Mojzisova G, Mirossay L, Mojzis J. Soy and breast cancer: focus on angiogenesis. International journal of molecular sciences. 2015;16(5):11728-49.

49. Bilir B, Sharma NV, Lee J, Hammarstrom B, Svindland A, Kucuk O, Moreno CS. Effects of genistein supplementation on genome-wide DNA methylation and gene expression in patients with localized prostate cancer. International journal of oncology. 2017;51(1):223-34
50. Yang Y, Zang A, Jia Y, Shang Y, Zhang Z, Ge K, Zhang J, Fan W, Wang B. Genistein inhibits A549 human lung cancer cell proliferation via miR-27a and MET signaling. Oncology letters. 2016;12(3):2189-93.

51. Yang YM, Yang Y, Dai WW, Li XM, Ma JQ, Tang LP. Genistein-induced apoptosis is mediated by endoplasmic reticulum stress in cervical cancer cells. Eur Rev Med Pharmacol Sci. 2016;20(15):3292-6.

52. Sahin K, Yenice E, Bilir B, Orhan C, Tuzcu M, Sahin N, Ozercan IH, Kabil N, Ozpolat B, Kucuk O. Genistein prevents development of spontaneous ovarian cancer and inhibits tumor growth in hen model. Cancer Prevention Research. 2019;12(3):135-46.

53. Li E, Zhang T, Sun X, Li Y, Geng H, Yu D, Zhong C. Sonic hedgehog pathway mediates genistein inhibition of renal cancer stem cells. Oncology letters. 2019;18(3):3081-91.

54. Zhang Q, Bao J, Yang J. Genistein-triggered anticancer activity against liver cancer cell line HepG2 involves ROS generation, mitochondrial apoptosis, G2/M cell cycle arrest and inhibition of cell migration. Archives of medical science: AMS. 2019;15(4):1001.

55. Park C, Cha HJ, Lee H, Hwang-Bo H, Ji SY, Kim MY, Hong SH, Jeong JW, Han $\mathrm{MH}$, Choi SH, Jin CY. Induction of G2/M cell cycle arrest and apoptosis by genistein in human bladder cancer T24 cells through inhibition of the ROS-dependent PI3k/Akt signal transduction pathway. Antioxidants. 2019;8(9):327.

56. Yin F, Giuliano AE, Van Herle AJ. Growth inhibitory effects of flavonoids in human thyroid cancer cell lines. Thyroid. 1999;9(4):369-76.

57. Singh G, Verma AK, Kumar V. Catalytic properties, functional attributes and industrial applications of $\beta$-glucosidases. 3 Biotech. 2016;6(1):3

58. Giske Ursin,1 Anna H. Wu,1 Robert N. Hoover,2 Dee W. West, 3 Abraham M. Y. Nomura, 4 Laurence N. Kolonel,4 Malcolm C. Pike,1 and Regina G. Ziegler2

59. Ursin G, Wu AH, Hoover RN, West DW, Nomura AM, Kolonel LN, Pike MC, Ziegler RG. Breast cancer and oral contraceptive use in Asian-American women. American journal of epidemiology. 1999;150(6):561-7.

60. Maj E, Papiernik D, Wietrzyk J. Antiangiogenic cancer treatment: The great discovery and greater complexity. International journal of oncology. 2016;49(5):1773-84.

61. Moyad MA, Sakr WA, Hirano D, Miller GJ. Complementary medicine for prostate cancer: effects of soy and fat consumption. Reviews in urology. 2001;3(Suppl 2):S20.

62. Mahmoud AM, Yang W, Bosland MC. Soy isoflavones and prostate cancer: a review of molecular mechanisms. The Journal of steroid biochemistry and molecular biology. 2014;140:116-32.

63. Seo YJ, Kim BS, Chun SY, Park YK, Kang KS, Kwon TG. Apoptotic effects of genistein, biochanin-A and apigenin on LNCaP and PC-3 cells by p21 through transcriptional inhibition of polo-like kinase-1. Journal of Korean Medical Science. 2011;26(11):1489.

64. Wang BF, Wang JS, Lu JF, Kao TH, Chen BH. Antiproliferation effect and mechanism of prostate cancer cell lines as affected by isoflavones from soybean cake. Journal of agricultural and food chemistry. 2009 Mar 25;57(6):2221-32

65. Li Y, Ahmed F, Ali S, Philip PA, Kucuk O, Sarkar FH. Inactivation of nuclear factor $\mathrm{KB}$ by soy isoflavone genistein contributes to increased apoptosis induced by chemotherapeutic agents in human cancer cells. Cancer research. 2005;65(15):6934-42.

66. Kuzu N, Metin K, Dagli AF, Akdemir F, Orhan C, Yalniz M, Ozercan IH, Sahin $\mathrm{K}$, Bahcecioglu IH. Protective role of genistein in acute liver damage induced by carbon tetrachloride. Mediators of inflammation. 2007;2007.

67. Tacyildiz N, Ozyoruk D, Yavuz G, Unal E, Dincaslan H, Dogu F, Sahin K, Kucuk O. Soy isoflavones ameliorate the adverse effects of chemotherapy in children. Nutrition and cancer. 2010;62(7):1001-5.

68. Andres A, Donovan SM, Kuhlenschmidt MS. Soy isoflavones and virus infections. The Journal of nutritional biochemistry. 2009;20(8):563-9.

69. David AV, Arulmoli R, Parasuraman S. Overviews of biological importance of quercetin: A bioactive flavonoid. Pharmacognosy reviews. 2016;10(20):84

70. O'Leary KA, Day AJ, Needs PW, Mellon FA, O'Brien NM, Williamson G. Metabolism of quercetin-7-and quercetin-3-glucuronides by an in vitro hepatic model: the role of human $\beta$-glucuronidase, sulfotransferase, catechol-O-methyltransferase and multi-resistant protein 2 (MRP2) in flavonoid metabolism. Biochemical pharmacology. 2003;65(3):479-91.

71. O'Leary KA, Day AJ, Needs PW, Sly WS, O'Brien NM, Williamson G. Flavonoid glucuronides are substrates for human liver $\beta$-glucuronidase. FEBS letters. 2001;503(1):103-6

72. Manach C, Williamson G, Morand C, Scalbert A, Rémésy C. Bioavailability and bioefficacy of polyphenols in humans. I. Review of 97 bioavailability studies. The American journal of clinical nutrition. 2005;81(1):230S-42S.

73. Li Y, Yao J, Han C, Yang J, Chaudhry MT, Wang S, Liu H, Yin Y. Quercetin, inflammation and immunity. Nutrients. 2016;8(3):167.

74. Metodiewa D, Jaiswal AK, Cenas N, Dickancaité E, Segura-Aguilar J. Quercetin may act as a cytotoxic prooxidant after its metabolic activation to semiquinone and quinoidal product. Free radical biology and medicine. 1999;26(1-2):107-16.

75. Gibellini L, Pinti M, Nasi M, Montagna JP, De Biasi S, Roat E, Bertoncelli L, Cooper EL, Cossarizza A. Quercetin and cancer chemoprevention. Evid Based Complement Alternat Med. 2011;2011:591356.

76. Nam JS, Sharma AR, Nguyen LT, Chakraborty C, Sharma G, Lee SS. Application of bioactive quercetin in oncotherapy: from nutrition to nanomedicine. Molecules. 2016;21(1):108. 
77. Zhang $\mathrm{Q}$, Zhao $\mathrm{XH}$, Wang ZJ. Cytotoxicity of flavones and flavonols to a human esophageal squamous cell carcinoma cell line (KYSE-510) by induction of G2/M arrest and apoptosis. Toxicology in vitro. 2009;23(5):797-807.

78. Matsuo M, Sasaki N, Saga K, Kaneko T. Cytotoxicity of flavonoids toward cultured normal human cells. Biological and Pharmaceutical Bulletin. 2005;28(2):253-9.

79. Brisdelli F, Di Francesco L, Giorgi A, Lizzi AR, Luzi C, Mignogna G, Bozzi A, Schininà ME. Proteomic Analysis of Quercetin-Treated K562 Cells. International journal of molecular sciences. 2020;21(1):32.

80. Jeong JH, An JY, Kwon YT, Rhee JG, Lee YJ. Effects of low dose quercetin: Cancer cell-specific inhibition of cell cycle progression. Journal of cellular biochemistry. 2009;106(1):73-82.

81. Krisanaprakornkit S, Iamaroon A. Epithelial-mesenchymal transition in oral squamous cell carcinoma. ISRN Oncol. 2012;2012:681469.

82. Watanabe A, Hosino D, Koshikawa N, Seiki M, Suzuki T, Ichikawa K. Critical role of transient activity of MT1-MMP for ECM degradation in invadopodia. PLoS Comput Biol. 2013;9(5):e1003086.

83. Kim SR, Lee EY, Kim DJ, Kim HJ, Park HR. Quercetin Inhibits Cell Survival and Metastatic Ability via the EMT-Mediated Pathway in Oral Squamous Cell Carcinoma. Molecules. 2020;25(3):757.

84. Jobin C, Bradham CA, Russo MP, Juma B, Narula AS, Brenner DA, Sartor RB. Curcumin blocks cytokine-mediated NF- $\mathrm{KB}$ activation and proinflammatory gene expression by inhibiting inhibitory factor I-kB kinase activity. The Journal of Immunology. 1999;163(6):3474-83.

85. Park CH, Chang JY, Hahm ER, Park S, Kim HK, Yang CH. Quercetin, a potent inhibitor against $\beta$-catenin/Tcf signaling in SW480 colon cancer cells. Biochemical and biophysical research communications. 2005;328(1):227-34.

86. Lugli E, Ferraresi R, Roat E, Troiano L, Pinti M, Nasi M, Nemes E, Bertoncelli L, Gibellini L, Salomoni P, Cooper EL. Quercetin inhibits lymphocyte activation and proliferation without inducing apoptosis in peripheral mononuclear cells. Leukemia research. 2009:33(1):140-50.

87. Basile D, Di Nardo P, Corvaja C, Garattini SK, Pelizzari G, Lisanti C, Bortot L, Da Ros L, Bartoletti M, Borghi M, Gerratana L. Mucosal injury during anti-cancer treatment: from pathobiology to bedside. Cancers. 2019;11(6):857.

88. Sukhotnik I, Moati D, Shaoul R, Loberman B, Pollak Y, Schwartz B. Quercetin prevents small intestinal damage and enhances intestinal recovery during methotrexate-induced intestinal mucositis of rats. Food \& nutrition research. 2018;62.

89. Mahoney SE, Davis JM, Murphy EA, McClellan JL, Pena MM. Dietary quercetin reduces chemotherapy-induced fatigue in mice. Integrative cancer therapies. 2014;13(5):417-24.

90. Mahoney SE, Davis JM, Murphy EA, McClellan JL, Gordon B, Pena MM. Effects of 5-fluorouracil chemotherapy on fatigue: role of MCP-1. Brain, behavior, and immunity. 2013;27:155-61.

91. Cheng SC, Huang WC, S Pang JH, Wu YH, Cheng CY. Quercetin inhibits the production of IL-1 $\beta$-induced inflammatory cytokines and chemokines in ARPE-19 cells via the MAPK and NF- $\mathrm{KB}$ signaling pathways. International journal of molecular sciences. 2019;20(12):2957.

92. Shanmugam MK, Rane G, Kanchi MM, Arfuso F, Chinnathambi A, Zayed ME, Alharbi SA, Tan BK, Kumar AP, Sethi G. The multifaceted role of curcumin in cancer prevention and treatment. Molecules. 2015;20(2):2728-69.

93. Prasad S, Tyagi AK, Siddik ZH, Aggarwal BB. Curcumin-free turmeric exhibits activity against human hct-116 colon tumor xenograft: comparison with curcumin and whole turmeric. Frontiers in pharmacology. 2017;8.

94. Anand P, Kunnumakkara AB, Newman RA, Aggarwal BB. Bioavailability of curcumin: problems and promises. Molecular pharmaceutics. 2007;4(6):807-18.

95. Shoba G, Joy D, Joseph T, Majeed M, Rajendran R, Srinivas PS. Influence of piperine on the pharmacokinetics of curcumin in animals and human volunteers. Planta medica. 1998;64:353-6.

96. Cuomo J, Appendino G, Dern AS, Schneider E, McKinnon TP, Brown MJ, Togni S, Dixon BM. Comparative absorption of a standardized curcuminoid mixture and its lecithin formulation. Journal of natural products. 2011;74(4):664-9.

97. Jäger R, Lowery RP, Calvanese AV, Joy JM, Purpura M, Wilson JM. Comparative absorption of curcumin formulations. Nutrition journal. 2014;13(1):1-8.

98. Dei Cas M, Ghidoni R. Dietary curcumin: correlation between bioavailability and health potential. Nutrients. 2019;11(9):2147.

99. Kuttan R, Sudheeran PC, Josph CD. Turmeric and curcumin as topical agents in cancer therapy. Tumori Journal. 1987;73(1):29-31.

100. Farzaei MH, Zobeiri M, Parvizi F, El-Senduny FF, Marmouzi I, Coy-Barrera E, Naseri R, Nabavi SM, Rahimi R, Abdollahi M. Curcumin in liver diseases: a systematic review of the cellular mechanisms of oxidative stress and clinical perspective. Nutrients. 2018;10(7):855

101. Carroll RE, Benya RV, Turgeon DK, Vareed S, Neuman M, Rodriguez L, Kakarala M, Carpenter PM, McLaren C, Meyskens FL, Brenner DE. Phase IIa clinical trial of curcumin for the prevention of colorectal neoplasia. Cancer prevention research. 2011;4(3):354-64.

102. Patel VB, Misra S, Patel BB, Majumdar AP Colorectal cancer: chemopreventive role of curcumin and resveratrol. Nutrition and cancer. 2010;62(7):958-67.

103. Sharma RA, Euden SA, Platton SL, Cooke DN, Shafayat A, Hewitt HR, Marczylo TH, Morgan B, Hemingway D, Plummer SM, Pirmohamed M. Phase I clinical trial of oral curcumin: biomarkers of systemic activity and compliance. Clinical Cancer Research. 2004;10(20):6847-54.
104. He ZY, Shi CB, Wen H, Li FL, Wang BL, Wang J. Upregulation of p53 expression in patients with colorectal cancer by administration of curcumin. Cancer investigation. 2011;29(3):208-13.

105. Um HD. Bcl-2 family proteins as regulators of cancer cell invasion and metastasis: a review focusing on mitochondrial respiration and reactive oxygen species. Oncotarget. 2016;7(5):5193.

106. Chen A, Madu CO, Lu Y. The Functional Role of Bcl-2 Family of Proteins in the Immune System and Cancer. Oncomedicine 2019;4:17-26.

107. Giordano A, Tommonaro G. Curcumin and cancer. Nutrients. 2019;11(10):2376.

108. Bachmeier BE, Killian PH, Melchart D. The role of curcumin in prevention and management of metastatic disease. International journal of molecular sciences. 2018;19(6):1716.

109. Jobin C, Bradham CA, Russo MP, Juma B, Narula AS, Brenner DA, Sartor RB. Curcumin blocks cytokine-mediated NF- $\mathrm{KB}$ activation and proinflammatory gene expression by inhibiting inhibitory factor I-kB kinase activity. The Journal of Immunology. 1999;163(6):3474-83.

110. Bachmeier BE, Killian PH, Melchart D. The role of curcumin in prevention and management of metastatic disease. International journal of molecular sciences. 2018;19(6):1716.

111. Vallée A, Lecarpentier Y, Vallée JN. Curcumin: a therapeutic strategy in cancers by inhibiting the canonical WNT/ $\beta$-catenin pathway. Journal of Experimental \& Clinical Cancer Research. 2019;38(1):1-6.

112. Shang $\mathrm{S}$, Hua F, Hu ZW. The regulation of $\beta$-catenin activity and function in cancer: therapeutic opportunities. Oncotarget. 2017;8(20):33972.

113. Xu MX, Zhao L, Deng C, Yang L, Wang Y, Guo T. et al. Curcumin suppresses proliferation and induces apoptosis of human hepatocellular carcinoma cells via the wnt signaling pathway. International journal of oncology. 2013;43:1951-9.

114. Zheng R, Deng Q, Liu Y, Zhao P. Curcumin inhibits gastric carcinoma cell growth and induces apoptosis by suppressing the Wnt/ $\beta$-catenin signaling pathway. Medical science monitor: international medical journal of experimental and clinical research. 2017;23:163

115. Trivedi S, Starz-Gaiano M. Drosophila Jak/STAT signaling: regulation and relevance in human cancer and metastasis. International journal of molecular sciences. 2018;19(12):4056.

116. Koppikar P, Lui VW, Man D, Xi S, Chai RL, Nelson E, Tobey AB, Grandis JR. Constitutive activation of signal transducer and activator of transcription 5 contributes to tumor growth, epithelial-mesenchymal transition, and resistance to epidermal growth factor receptor targeting. Clinical Cancer Research. 2008;14(23):7682-90.

117. Li Y, Sun W, Han N, Zou Y, Yin D. Curcumin inhibits proliferation, migration, invasion and promotes apoptosis of retinoblastoma cell lines through modulation of miR-99a and JAK/STAT pathway. BMC cancer. 2018;18(1):1-9.

118. Hu A, Huang JJ, Jin XJ, Li JP, Tang YJ, Huang XF, Cui HJ, Xu WH, Sun GB. Curcumin suppresses invasiveness and vasculogenic mimicry of squamous cell carcinoma of the larynx through the inhibition of JAK-2/STAT-3 signaling pathway. American journal of cancer research. 2015;5(1):278.

119. Jiang N, Dai Q, Su X, Fu J, Feng X, Peng J. Role of PI3K/AKT pathway in cancer: the framework of malignant behavior. Molecular biology reports. 2020;47(6):4587-629.

120. Xu F, Na L, Li Y, Chen L. Roles of the PI3K/AKT/mTOR signalling pathways in neurodegenerative diseases and tumours. Cell \& bioscience. 2020;10:1-2.

121. Luo J, Manning BD, Cantley LC. Targeting the PI3K-Akt pathway in human cancer: rationale and promise. Cancer cell. 2003;4(4):257-62.

122. Kapinova A, Kubatka P, Golubnitschaja O, Kello M, Zubor P, Solar P, Pec M. Dietary phytochemicals in breast cancer research: anticancer effects and potential utility for effective chemoprevention. Environ Health Prev Med. 2018;23(1):36.

123. Hu S, Xu Y, Meng L, Huang L, Sun H. Curcumin inhibits proliferation and promotes apoptosis of breast cancer cells. Experimental and therapeutic medicine. 2018;16:1266-72.

124. Liu Z, Huang P, Law S, Tian H, Leung W, Xu C. Preventive effect of curcumin against chemotherapy-induced side-effects. Frontiers in pharmacology. 2018:9:1374.

125. Yao Q, Ye X, Wang L, Gu J, Fu T, Wang Y, Lai Y, Wang Y, Wang X, Jin H, Guo $Y$. Protective effect of curcumin on chemotherapy-induced intestinal dysfunction. International journal of clinical and experimental pathology. 2013;6(11):2342.

126. Mendonça LM, Dos Santos GC, Antonucci GA, Dos Santos AC, Bianchi MD, Antunes LM. Evaluation of the cytotoxicity and genotoxicity of curcumin in PC12 cells. Mutation Research/Genetic Toxicology and Environmental Mutagenesis. 2009;675(1-2):29-34

127. Mendonça LM, da Silva Machado C, Teixeira CC, de Freitas LA, Bianchi MD, Antunes LM. Curcumin reduces cisplatin-induced neurotoxicity in NGF-differentiated PC12 cells. Neurotoxicology. 2013:34:205-11.

128. Carey PJ. Drug-induced myelosuppression. Drug safety. 2003;26(10):691-706.

129. Chen X, Wang J, Fu Z, Zhu B, Wang J, Guan S, Hua Z. Curcumin activates DNA repair pathway in bone marrow to improve carboplatin-induced myelosuppression. Scientific reports. 2017;7(1):1-1.

130. Reygaert WC. Green tea catechins: Their use in treating and preventing infectious diseases. BioMed research international. 2018.2018.

131. Narumi K, Sonoda JI, Shiotani K, Shigeru M, Shibata M, Kawachi A, Tomishige E, Sato K, Motoya T. Simultaneous detection of green tea catechins and gallic acid in human serum after ingestion of green tea tablets using 
ion-pair high-performance liquid chromatography with electrochemical detection. Journal of Chromatography B. 2014;945:147-53.

132. Chow HH, Hakim IA. Pharmacokinetic and chemoprevention studies on tea in humans. Pharmacological research. 2011;64(2):105-12.

133. Cai ZY, Li XM, Liang JP, Xiang LP, Wang KR, Shi YL, Yang R, Shi M, Ye JH, Lu JL, Zheng XQ. Bioavailability of tea catechins and its improvement. Molecules. 2018;23(9):2346.

134. Hong J, Lambert JD, Lee SH, Sinko PJ, Yang CS. Involvement of multidrug resistance-associated proteins in regulating cellular levels of (-)-epigallocatechin-3-gallate and its methyl metabolites. Biochem Biophys Res Commun. 2003;310(1):222-7.

135. Ye JH, Augustin MA. Nano-and micro-particles for delivery of catechins: Physical and biological performance. Critical reviews in food science and nutrition. 2019;59(10):1563-79.

136. Dag D, Oztop MH. Formation and characterization of green tea extract loaded liposomes. Journal of food science. 2017;82(2):463-70.

137. Li Y, Lim LT, Kakuda Y. Electrospun zein fibers as carriers to stabilize (-)epigallocatechin gallate. Journal of food science. 2009;74(3):C233-40.

138. Dube A, Nicolazzo JA, Larson I. Chitosan nanoparticles enhance the plasma exposure of (-)-epigallocatechin gallate in mice through an enhancement in intestinal stability. European Journal of Pharmaceutical Sciences. 2011;44(3):422-6

139. Lambert JD, Sang S, Hong J, Kwon SJ, Lee MJ, Ho CT, Yang CS. Peracetylation as a means of enhancing in vitro bioactivity and bioavailability of epigallocatechin-3-gallate. Drug metabolism and disposition. 2006;34(12):2111-6

140. Vittorio O, Brandl M, Cirillo G, Kimpton K, Hinde E, Gaus K, Yee E, Kumar N, Duong $\mathrm{H}$, Fleming C, Haber M. Dextran-Catechin: An anticancer chemically-modified natural compound targeting copper that attenuates neuroblastoma growth. Oncotarget. 2016;7(30):47479.

141. Ranjan A, Ramachandran S, Gupta N, Kaushik I, Wright S, Srivastava S, Das H, Srivastava S, Prasad S, Srivastava SK. Role of Phytochemicals in Cancer Prevention. Int J Mol Sci. 2019;20(20):4981.

142. Sheng J, Shi W, Guo H, Long W, Wang Y, Qi J, Liu J, Xu Y. The inhibitory effect of (-)-epigallocatechin-3-gallate on breast cancer progression via reducing SCUBE2 methylation and DNMT activity. Molecules. 2019;24(16):2899.

143. Orentas RJ. Reading the tea leaves of tumor-mediated immunosuppression. Clinical Cancer Research. 2013;19(5):955-7.

144. Yan Y, Cook J, McQuillan J, Zhang G, Hitzman CJ, Wang Y, Wiedmann TS, You M. Chemopreventive effect of aerosolized polyphenon $\mathrm{E}$ on lung tumorigenesis in A/J mice. Neoplasia. 2007;9(5):401-5.

145. Du GJ, Zhang Z, Wen XD, Yu C, Calway T, Yuan CS, Wang CZ. Epigallocatechin Gallate (EGCG) is the most effective cancer chemopreventive polyphenol in green tea. Nutrients. 2012;4(11):1679-91.

146. Santilli G, Piotrowska I, Cantilena S, Chayka O, D'Alicarnasso M, Morgenstern DA, Himoudi N, Pearson K, Anderson J, Thrasher AJ, Sala A. Polyphenol E enhances the antitumor immune response in neuroblastoma by inactivating myeloid suppressor cells. Clinical cancer research. 2013;19(5):1116-25.

147. Fang CY, Wu CC, Hsu HY, Chuang HY, Huang SY, Tsai CH, Chang Y, Tsao GS, Chen CL, Chen JY. EGCG inhibits proliferation, invasiveness and tumor growth by up-regulation of adhesion molecules, suppression of gelatinases activity, and induction of apoptosis in nasopharyngeal carcinoma cells. International journal of molecular sciences. 2015;16(2):2530-58

148. Chen Y, Wang XQ, Zhang Q, Zhu JY, Li Y, Xie CF, Li XT, Wu JS, Geng SS, Zhong CY, Han HY. (-)-Epigallocatechin-3-gallate inhibits colorectal cancer stem cells by suppressing Wnt/ $\beta$-catenin pathway. Nutrients. 2017;9(6):572.

149. Taketo MM. Shutting down wnt signal-activated cancer. Nature genetics. 2004:36(4):320-2.

150. Shin YS, Kang SU, Park JK, Kim YE, Kim YS, Baek SJ, Lee SH, Kim CH. Anti-cancer effect of (-)-epigallocatechin-3-gallate (EGCG) in head and neck cancer through repression of transactivation and enhanced degradation of $\beta$-catenin. Phytomedicine. 2016;23(12):1344-55.

151. Cheng CW, Shieh PC, Lin YC, Chen YJ, Lin YH, Kuo DH, Liu JY, Kao JY, Kao MC, Way TD. Indoleamine 2, 3-dioxygenase, an immunomodulatory protein, is suppressed by (-)-epigallocatechin-3-gallate via blocking of $\gamma$-interferon-induced JAK-PKC- $\delta$-STAT1 signaling in human oral cancer cells. Journal of agricultural and food chemistry. 2010;58(2):887-94.

152. Tian M, Tian D, Qiao X, Li J, Zhang L. Modulation of Myb-induced NF-kBSTAT3 signaling and resulting cisplatin resistance in ovarian cancer by dietary factors. Journal of cellular physiology. 2019;234(11):21126-34.

153. Deb G, Shankar E, Thakur VS, Ponsky LE, Bodner DR, Fu P, Gupta S. Green tea-induced epigenetic reactivation of tissue inhibitor of matrix metalloproteinase- 3 suppresses prostate cancer progression through histonemodifying enzymes. Molecular carcinogenesis. 2019;58(7):1194-207.

154. Ying L, Yan F, Williams BR, Xu P, Li X, Zhao Y, Hu Y, Wang Y, Xu D, Dai J. (-)-Epigallocatechin-3-gallate and EZH 2 inhibitor GSK 343 have similar inhibitory effects and mechanisms of action on colorectal cancer cells. Clinical and Experimental Pharmacology and Physiology. 2018;45(1):58-67.

155. Ikushima H, Miyazono K. TGF $\beta$ signaling: a complex web in cancer progression. Nature reviews cancer. 2010;10(6):415-24.

156. Brandl M, Seidler B, Haller F, Adamski J, Schmid RM, Saur D, Schneider G. IKKa controls canonical TGF $\beta$-SMAD signaling to regulate genes expressing SNAIL and SLUG during EMT in Panc1 cells. Journal of cell science. 2010;123(24):4231-9.
157. Li T, Zhao N, Lu J, Zhu Q, Liu X, Hao F, Jiao X. Epigallocatechin gallate (EGCG) suppresses epithelial-Mesenchymal transition (EMT) and invasion in anaplastic thyroid carcinoma cells through blocking of TGF- $\beta 1 / \mathrm{Smad}$ signaling pathways. Bioengineered. 2019;10(1):282-91.

158. Jiang P, Xu C, Chen L, Chen A, Wu X, Zhou M, Haq IU, Mariyam Z, Feng Q. EGCG inhibits CSC-like properties through targeting miR-485/CD44 axis in A549-cisplatin resistant cells. Molecular carcinogenesis. 2018;57(12):1835-44

159. Waterhouse DN, Sutherland BW, Dos Santos N, Masin D, Osooly M, Strutt D, Ostlund C, Anantha M, Harasym N, Manisali I, Wehbe M. Irinophore CTM, a lipid nanoparticle formulation of irinotecan, abrogates the gastrointestinal effects of irinotecan in a rat model of clinical toxicities. Investigational new drugs. 2014;32(6):1071-82.

160. Sangeetha $P$, Das UN, Koratkar R, Suryaprabha P. Increase in free radical generation and lipid peroxidation following chemotherapy in patients with cancer. Free Radical Biology and Medicine. 1990;8(1):15-9.

161. Sawyer TE, Bonner JA. The interaction of buthionine sulphoximide (BSO) and the topoisomerase I inhibitor CPT-11. The British journal of cancer. Supplement. 1996;27:S109.

162. Wessner B, Strasser EM, Koitz N, Schmuckenschlager C, Unger-Manhart N, Roth E. Green tea polyphenol administration partly ameliorates chemotherapy-induced side effects in the small intestine of mice. The Journal of nutrition. 2007;137(3):634-40.

163. Thorn CF, Oshiro C, Marsh S, Hernandez-Boussard T, McLeod H, Klein TE, Altman RB. Doxorubicin pathways: pharmacodynamics and adverse effects. Pharmacogenetics and genomics. 2011;21(7):440.

164. Larsen EC, Muiller J, Schmiegelow K, Rechnitzer C, Andersen AN. Reduced ovarian function in long-term survivors of radiation-and chemotherapy-treated childhood cancer. The Journal of Clinical Endocrinology \& Metabolism. 2003;88(11):5307-14.

165. Fabbri R, Macciocca M, Vicenti R, Caprara G, Piccinni MP, Paradisi R, Terzano $P$, Papi A, Seracchioli R. Epigallocatechin-3-gallate inhibits doxorubicin-induced inflammation on human ovarian tissue. Bioscience reports. 2019;39(5)

166. Parhiz H, Roohbakhsh A, Soltani F, Rezaee R, Iranshahi M. Antioxidant and anti-inflammatory properties of the citrus flavonoids hesperidin and hesperetin: an updated review of their molecular mechanisms and experimental models. Phytotherapy Research. 2015;29(3):323-31.

167. Ameer B, Weintraub RA, Johnson JV, Yost RA, Rouseff RL. Flavanone absorption after naringin, hesperidin, and citrus administration. Clinical Pharmacology \& Therapeutics. 1996;60(1):34-40.

168. Manach C1, Morand C, Gil-Izquierdo A, Bouteloup-Demange C, Remesy C. Bioavailability in humans of the flavanones hesperidin and narirutin after the ingestion of two doses of orange juice. European journal of clinical nutrition. 2003;57(2):235-42.

169. Kanaze FI, Bounartzi MI, Georgarakis M, Niopas I. Pharmacokinetics of the citrus flavanone aglycones hesperetin and naringenin after single oral administration in human subjects. European journal of clinical nutrition. 2007;61(4):472-7.

170. Tanaka T, Makita H, Kawabata K, Mori H, Kakumoto M, Satoh K, Hara A, Sumida T, Tanaka T, Ogawa H. Chemoprevention of azoxymethane-induced rat colon carcinogenesis by the naturally occurring flavonoids, diosmin and hesperidin. Carcinogenesis. 1997;18(5):957-65.

171. Banjerdpongchai R, Wudtiwai B, Khaw-On P, Rachakhom W, Duangnil N, Kongtawelert P. Hesperidin from Citrus seed induces human hepatocellular carcinoma HepG2 cell apoptosis via both mitochondrial and death receptor pathways. Tumor Biology. 2016;37(1):227-37.

172. Miyagi Y, Om AS, Chee KM, Bennink MR. Inhibition of azoxymethane-induced colon cancer by orange juice. Nutrition and cancer. 2000:36(2):224-9.

173. Guthrie N, Carroll KK. Inhibition of mammary cancer by citrus flavonoids. Flavonoids in the living system. 1998;439:227-36.

174. Pillai MG, Thampi BS, Menon VP, Leelamma S. Influence of dietary fiber from coconut kernel (Cocos nucifera) on the 1, 2-dimethylhydrazine-induced lipid peroxidation in rats. The Journal of nutritional biochemistry. 1999;10(9):555-60.

175. Aranganathan S, Selvam JP, Nalini N. Hesperetin exerts dose dependent chemopreventive effect against 1, 2-dimethyl hydrazine induced rat colon carcinogenesis. Investigational new drugs. 2009;27(3):203-13

176. Bobek P, Galbavy S. Influence of inulin on dimethylhydrazine-induced carcinogenesis and antioxidant enzymatic system in rat. Biologia. 2001;56(3):287-91.

177. Pretlow TP, Barrow BJ, Ashton WS, O'Riordan MA, Pretlow TG, Jurcisek JA, Stellato TA. Aberrant crypts: putative preneoplastic foci in human colonic mucosa. Cancer research. 1991;51(5):1564-7.

178. Harada S, Fujii C, Hayashi A, Ohkoshi N. An association between idiopathic Parkinson's disease and polymorphisms of phase II detoxification enzymes: glutathione S-transferase M1 and quinone oxidoreductase 1 and 2 . Biochemical and biophysical research communications. 2001;288(4):887-92.

179. Bodduluru LN, Kasala ER, Barua CC, Karnam KC, Dahiya V, Ellutla M. Antiproliferative and antioxidant potential of hesperetin against benzo (a) pyrene-induced lung carcinogenesis in Swiss albino mice. Chemico-biological interactions. 2015;242:345-52.

180. Shirzad M, Heidarian E, Beshkar P, Gholami-Arjenaki M. Biological effects of hesperetin on interleukin-6/phosphorylated signal transducer and activator of transcription 3 pathway signaling in prostate cancer PC3 cells. Pharmacognosy research. 2017;9(2):188. 
181. Boojar MM, Boojar MM, Golmohammad S, Bahrehbar I. Data on cell survival, apoptosis, ceramide metabolism and oxidative stress in A-494 renal cell carcinoma cell line treated with hesperetin and hesperetin-7-O-acetate. Data in brief. 2018;20:596-601.

182. Li L, Davie JR. The role of Sp1 and Sp3 in normal and cancer cell biology. Annals of Anatomy-Anatomischer Anzeiger. 2010;192(5):275-83.

183. Safe S, Abdelrahim M. Sp transcription factor family and its role in cancer. European journal of cancer. 2005;41(16):2438-48.

184. Lee KA, Lee SH, Lee YJ, Baeg SM, Shim JH. Hesperidin induces apoptosis by inhibiting Sp1 and its regulatory protein in MSTO-211H cells. Biomolecules \& therapeutics. 2012;20(3):273.

185. Park HJ, Kim MJ, Ha E, Chung JH. Apoptotic effect of hesperidin through caspase3 activation in human colon cancer cells, SNU-C4. Phytomedicine. 2008;15(1-2):147-51.

186. Yeh MH, Kao ST, Hung CM, Liu CJ, Lee KH, Yeh CC. Hesperidin inhibited acetaldehyde-induced matrix metalloproteinase- 9 gene expression in human hepatocellular carcinoma cells. Toxicology letters. 2009;184(3):204-10.

187. Natarajan N, Thamaraiselvan R, Lingaiah H, Srinivasan P, Periyasamy BM. Effect of flavonone hesperidin on the apoptosis of human mammary carcinoma cell line MCF-7. Biomedicine \& Preventive Nutrition. 2011;1(3):207-15.

188. Mahmoud AM, Mohammed HM, Khadrawy SM, Galaly SR. Hesperidin protects against chemically induced hepatocarcinogenesis via modulation of Nrf2/ARE/HO-1, PPARY and TGF- $31 /$ Smad3 signaling, and amelioration of oxidative stress and inflammation. Chemico-Biological Interactions. 2017;277:146-58.

189. Zhao X, Liu J, Feng L, Ge S, Yang S, Chen C, Li X, Peng L, Mu Y, Wang Y, Gu D. Anti-angiogenic effects of Qingdu granule on breast cancer through inhibiting NFAT signaling pathway. Journal of ethnopharmacology. 2018;222:261-9.

190. Polat N, Ciftci O, Cetin A, Yylmaz T. Toxic effects of systemic cisplatin on rat eyes and the protective effect of hesperidin against this toxicity. Cutaneous and ocular toxicology. 2016;35(1):1-7.

191. Omar HA, Mohamed WR, Arafa ES, Shehata BA, El Sherbiny GA, Arab HH, Elgendy AN. Hesperidin alleviates cisplatin-induced hepatotoxicity in rats without inhibiting its antitumor activity. Pharmacological Reports. 2016;68(2):349-56.

192. Rothenberg ML, Meropol NJ, Poplin EA, Van Cutsem E, Wadler S. Mortality associated with irinotecan plus bolus fluorouracil/leucovorin: summary findings of an independent panel. Journal of Clinical Oncology. 2001:19(18):3801-7.

193. Koklesova L, Liskova A, Samec M, Qaradakhi T, Zulli A, Smejkal K, Kajo K, Jakubikova J, Behzadi P, Pec M, Zubor P. Genoprotective activities of plant natural substances in cancer and chemopreventive strategies in the context of 3P medicine. EPMA Journal. 2020:11:261-87.

194. Qian S, Golubnitschaja O, Zhan X. Chronic inflammation: Key player and biomarker-set to predict and prevent cancer development and progression based on individualized patient profiles. Epma Journal. 2019;10(4):365-81. 